\title{
Dyspnea and Exercise Testing in Workers Exposed to Silica
}

\author{
Xiaorong WANG ${ }^{1,3)}$, Shunichi ARAKI ${ }^{1)}$, Eiji YANO ${ }^{2)}$, \\ Mianzheng WANG ${ }^{3)}$ and Zhiming WANG ${ }^{3)}$
}

1) Department of Public Health, Faculty of Medicine, The University of Tokyo, Japan

2) Department of Hygiene and Public Health, Teikyo University School of

Medicine, Japan

3) Department of Occupational Medicine, School of Public Health, West China

University of Medical Sciences, China

(Received July 14, 1995 and in revised form October 13, 1995)

\begin{abstract}
In order to provide a better objective assessment of exertional dyspnea and functional impairment due to exposure to silica, 153 workers exposed to silica dust (workers) and 62 patients with silicosis (patients) were performed the medical questionnaires with special reference to exertional dyspnea and exercise testing on bicycle ergometer. Complaints of breathlessness were present in $77(50 \%)$ workers and $53(85 \%)$ patients. The findings of exercise tests indicated that there were definite correlations between index of dyspnea (ID), or breathing reserve (BR) and complaint of breathlessness in both the workers and patients. ID increased and BR decreased with the increasing degree of breathlessness. We defined ID $>70 \%$ or $\mathrm{BR}<25 \mathrm{l} / \mathrm{min}$ as abnormal criteria and checked the ratios of dyspnea quantified objectively. Thus, $30 \%$ of the workers and $56 \%$ of the patients in this study were verified to have slight or moderate breathlessness, which were considerably lower than that derived from questionnaire on dyspnea. Our results suggest that objective physiological measures like exercise testing may be of value in evaluating dyspnea in workers exposed to silica.
\end{abstract}

Key words: Dyspnea - Exposed to silica - Exercise testing - Index of dyspnea (ID) Breathing reserve (BR)

\section{INTRODUCTION}

Dyspnea is perhaps the most common symptom complained by workers exposed to silica dust. It is frequently associated with the decrease in labor capacity.

Address correspondence to: Shunichi Araki, MD, Department of Public Health, Faculty of Medicine, The University of Tokyo, 7-3-1 Hongo, Bunkyo-ku, Tokyo 113, Japan

Reprint Requests to Shunichi Araki, MD 
However, dyspnea is a subjective sensation that similar ventilatory stresses can elicit variable subjective responses in different persons. The subjective complaint of dyspnea has been found to correlate poorly with objectively measured indices of physiologic impairment ${ }^{1,2)}$. In China, like many other countries, determination of functional impairment in subjects with silica exposure is necessary before any financial compensation and work rearrangement. Dyspnea, as an indicator of functional impairment, appears to be sensitive but nonspecific. Because the cause and genuineness of dyspnea are often disputed, compensation for respiratory disability in silica-exposed workers is a frequent cause of medico-legal controversy. It is very important to search for some objective physiologic indices to assess extent of dyspnea quantitatively. So far, there have been some studies reported association between complaints of dyspnea and resting pulmonary function in workers exposed to silica ${ }^{3,4)}$, but few referred to exercise testing. The present study was designed to examine the role of exercise testing in evaluating dyspnea among the workers exposed to silica dust and to provide a better objective index for evaluating exertional dyspnea.

\section{Subjects And Methods}

In October, 1989, two hundred workers directly exposed to silica dust and one hundred patients with silicosis were examined in order to determine the extent of respiratory impairment related to silica exposure. All the subjects had been engaged in manufacturing fire-proof bricks in an iron-steel plant located in Sichuan Province of China. Although there was no satisfactory annual measurement of dust concentration available, the concentration of total dust to which these workers were exposed had nearly always been above $4 \mathrm{mg} / \mathrm{m}^{3}$ (area sampling). The proportion of total silica in the dust was around $85 \%$. By the time of examination, the workers had been exposed to silica for at least 3 years, and there was no obvious roentgenographic evidence of pneumoconiosis on their chest $x$-ray films. The patients with silicosis were those who had definite evidence of silicosis on their chest roentgenographic films and were officially diagnosed as I-III grade silicosis by the Committee of Pneumoconiosis Diagnosis of Sichuan Province. The following evaluations were done in the 200 workers and 100 patients with silicosis: (1) a complete history including detailed occupational history and physical examination; (2) posteroanterior chest radiographs; (3) questionnaires on complaint of dyspnea; (4) a resting pulmonary function testing; (5) an exercise testing on bicycle ergometer. Of these examined subjects, 153 (77\%) workers and $62(62 \%)$ silicosis patients could perform the exercise testing on bicycle ergometer. Whereas the remaining 45 workers and 30 patients couldn't perform the exercise testing because of unfamiliarity with bicycling and with other diseases. Two workers and 8 patients were thought to be unsuitable to perform such exercise test because they 
complained severe dyspnea (grade 3, see the definition in the following). Altogether 47 workers and 38 patients were excluded. So, we selected and analyzed the data of 153 workers exposed to silica and 62 patients with silicosis in this study. All subjects were male. Nearly half of workers and $45 \%$ patients are smokers who were not excluded in the study. The mean age of 153 workers was $43 \mathrm{yr}(23-70 \mathrm{yr})$, while the patients was $53 \mathrm{yr}(38-72 \mathrm{yr})$. The mean length of exposure to silica was $16 \pm 8 \mathrm{yr}(3-36 \mathrm{yr})$ for workers and $20 \pm 8 \mathrm{yr}(15-40)$ for patients (Table 1).

The occupational history included a complete job history. All the subjects selected were not regularly exposed to other industrial toxins. Silica dust exposure was expressed according to duration of exposure and quantitative nature of exposure. Radiographic findings on chest roentgenogram were categorized 0 (no abnormal), I-I ${ }^{+}$(mild), II- $\mathrm{II}^{+}$(moderate), and III-III ${ }^{+}$(severe) according to the Radiographic Classification of Pneumoconiosis of China (1986). (The Chinese Classification was based on the 1980 ILO Classification. The categories 0, I, II, and III were comparable to categories $0,1,2$, and 3 respectively, in the 1980 ILO Classification). The obvious evidence of silicosis was not observed on their chest radiographs in the 153 workers. Of 62 patients, radiographic findings in 50 patients were categorized grade $\mathrm{I}_{-} \mathrm{I}^{+}$(mild), 12 patients were grade $\mathrm{II}-\mathrm{II}^{+}$(moderate). Complaint of dyspnea was graded as follows: 0 . none; 1 . more breathless than persons of same age while climbing hill or hurrying; 2 . breathless while performing ordinary tasks at work or while walking on level and 3. short of breath at rest or while undressing.

Lung function tests were carried out using a water-sealed spirometer (Godart, The Netherlands). Only $\mathrm{FEV}_{1}$ was used to estimate indirectly MVV in the study. The exercise study was performed with subject sitting on a bicycle ergometer. Dynamic spirometry was performed using a Godart Spirometer (The Netherlands). The ECG was recorded before and after exercise testing. The subjects with cardiac, vascular disorders were not allowed to perform exercise testing. Before the exercise, respiratory rate, heart rate and blood pressure in subjects were taken. The

Table 1. Subjects of Study

\begin{tabular}{lccccc}
\hline & \multicolumn{2}{c}{ Workers $(\mathrm{n}=153)$} & & \multicolumn{2}{c}{ Patients $(\mathrm{n}=62)$} \\
\cline { 2 - 3 } \cline { 5 - 6 } & mean & SD & & mean & SD \\
\hline Age $(\mathrm{yr})$ & 42.9 & 10.6 & & 53.3 & 8.9 \\
Weight $(\mathrm{kg})$ & 57.7 & 7.2 & & 55.1 & 6.9 \\
Height $(\mathrm{cm})$ & 164.3 & 5.7 & & 163.4 & 5.4 \\
Exposure (yr) & 15.5 & 7.8 & & 20.4 & 8.2 \\
Smoking (pack-yr) & 18.5 & 8.9 & & 16.3 & 11.1 \\
\hline
\end{tabular}


progressive work test used 20-watts increments each minute for the bicycle ergometer subjects. The cycling frequencies were kept $60 \mathrm{c} / \mathrm{min}$. The exercise was stopped when the subject indicated that he could no longer continue because of dyspnea, fatigue or other reasons, or when sub-maximal exercise was achieved. The sub-maximal exercise was considered being achieved when the subject performed load work up to 120 watts within 6 minutes. As soon as stopping exercise, the subjects were immediately taken respiratory rate, heart rate, blood pressure and recorded ECG once again.

The following indices were obtained from the spirograph curves: minute exercise ventilation $\left(\dot{\mathrm{V}}_{\mathrm{E}}\right)$, maximal exercise ventilation $\left(\dot{\mathrm{V}}_{\mathrm{E}} \mathrm{max}\right)$, minute uptaking oxygen capacity $\left(\dot{\mathrm{V}}_{2}\right)$ and maximal uptaking oxygen capacity $\left(\dot{\mathrm{V}}_{2} \mathrm{max}\right)$. Index of dyspnea (ID) expressing use of a proportion of potential maximal ventilatory capacity at the end of exercise was calculated from $\dot{\mathrm{V}}_{\mathrm{E}} \max / \mathrm{MVV} \times 100 \%$. Breathing reserve (BR), i.e., the unused fraction of potential ventilation at the maximal work level was derived from MVV $-\dot{\mathrm{V}}_{\mathrm{E}} \max$. MVV was calculated from $\mathrm{FEV}_{1}$ x 40 .

Exercise pulmonary function data were presented as mean and a SD. Statistical test was performed by student's $t$-test and one way analysis of variance (ANOVA). The relation between subjective dyspnea and measures of exercising lung function was examined by linear regression. P-values of $<0.05$ were considered significant.

\section{RESULTS}

In exercise testing, the number of subjects achieved sub-maximal exercise amount were more in the workers (67\%) than in the patients $(23 \%)$. The main reasons of stopping exercise before sub-maximal amount achieved were dyspnea and fatigue. However, the mean exercise time and exercise amount performed were not significantly different between the workers (5.6 minutes and 110 watts) and the patients ( 5 minutes and 97 watts) ( $\mathrm{p}>0.05$ ).

The physiologic data obtained from exercise testing are shown in Table 2. Respiratory rate, heart rate and systolic pressure for both groups were obviously increased after performing exercise. However, respiratory rate in the patients was higher than that in the workers either prior to or posterior to the exercise and the differences had statistical significance $(\mathrm{p}<0.01)$. The difference of heart rate was not significant between the two groups. Systolic pressure in the patients was significantly higher prior to the exercise, but lower posterior to the exercise than that in the workers $(\mathrm{p}<0.05)$. The workers and patients had similar diastolic pressure at rest. After performing exercise testing, patients' diastolic pressure was significantly higher $(\mathrm{p}<0.05)$ than that of prior to exercise testing.

Exercise pulmonary function data are presented in Table 3 . The mean value of ID was 55.8 (range, 29.5-85.6) in the workers, while 72.5 (range, 36.1-118.1) 
Table 2. Physiologic data of exercise testing.

\begin{tabular}{lccccc}
\hline Group & $\begin{array}{c}\text { Exercise } \\
\text { level }\end{array}$ & $\begin{array}{c}\text { Respiratory Rate } \\
\text { breaths/min }\end{array}$ & Heart Rate & \multicolumn{2}{c}{ Blood Pressure } \\
bystolic $/$ min & $\begin{array}{c}\text { Diastolic } \\
\text { mmHg }\end{array}$ & $\begin{array}{c}\text { mmHg } \\
\text { Workers }\end{array}$ \\
& $\mathrm{R}$ & $18 \pm 4^{*}$ & $72 \pm 10$ & $114 \pm 15^{*}$ & $75 \pm 9$ \\
\multirow{3}{*}{ Patients } & $\mathrm{E}$ & $30 \pm 6^{* *}$ & $110 \pm 22$ & $155 \pm 21^{*}$ & $75 \pm 9^{*}$ \\
& $\mathrm{R}$ & $20 \pm 4$ & $73 \pm 12$ & $119 \pm 18$ & $75 \pm 10$ \\
& $\mathrm{E}$ & $33 \pm 6$ & $111 \pm 23$ & $147 \pm 22$ & $79 \pm 12$ \\
\hline
\end{tabular}

$\mathrm{R}$ : taken at rest; E: taken in the moment stopping exercise.

$* \mathrm{P}<0.05, * * \mathrm{P}<0.01$ comparing workers and patients.

Table 3. Exercise pulmonary function.

\begin{tabular}{lcccccc}
\hline Group & $\begin{array}{c}\text { ID } \\
(\%)\end{array}$ & $\begin{array}{c}\mathrm{BR} \\
(\mathrm{l} / \mathrm{min})\end{array}$ & $\begin{array}{c}\dot{\mathrm{V}}_{\mathrm{E}} \\
(\mathrm{l} / \mathrm{min})\end{array}$ & $\begin{array}{c}\dot{\mathrm{V}}_{\mathrm{E}} \max \\
(\mathrm{l} / \mathrm{min})\end{array}$ & $\begin{array}{c}\dot{\mathrm{V}}_{\mathrm{O}_{2}} \\
(\mathrm{ml} / \mathrm{min})\end{array}$ & $\begin{array}{c}\dot{\mathrm{V}}_{\mathrm{o}_{2} \max } \\
(\mathrm{ml} / \mathrm{min})\end{array}$ \\
\hline Workers & $55.8+17.1^{*}$ & $48.9+17.8^{*}$ & $18.6+4.9$ & $54.3+14.4$ & $797.7+169.5^{*}$ & $1420.4+290.5^{*}$ \\
Patients & $72.5+23.8$ & $27.8+11.5$ & $17.4+3.5$ & $52.7+12.1$ & $744.1+163.6$ & $1341.1+347.7$ \\
\hline
\end{tabular}

$* \mathrm{P}<0.05$ comparing workers and patients.

in the patients. On the contrary, BR was 48.9 (range, 16.2-89.5) in the workers and 27.8 (range, 14.7-62.5) in the patients. The mean values of $\dot{\mathrm{V}}_{\mathrm{E}}, \dot{\mathrm{V}}_{\mathrm{E}} \mathrm{max}$ were higher in the workers than in the patients, although the difference was not statistically significant $(\mathrm{P}>0.05)$. Both of $\dot{\mathrm{V}}_{2}$ and $\dot{\mathrm{V}}_{2} \max$ were increased in the workers. Statistical analysis demonstrated significant differences between the workers and patients in ID, BR, $\dot{\mathrm{V}}_{2}$ and $\dot{\mathrm{V}}_{2} \max$.

Results of symptom on the questionnaire showed that complaints of breathlessness were present in $77(50 \%)$ workers and $53(85 \%)$ patients. We compared the mean values of the indices from exercise testing among the three groups which categorized according to the degree of breathlessness. (There was no grade 3 of breathlessness in this study.) There was a tendency that the higher grade of breathlessness was accompanied by the age. More importantly, ID increased and BR decreased with the increasing degree of breathlessness for both workers and the patients (Table 4). However, no relationship was detectable between $\dot{\mathrm{V}}_{\mathrm{E}} \mathrm{max}$, $\dot{V}_{\mathrm{O}_{2}} \max$ and the degree of breathlessness. Statistical analysis showed that there was no difference in $\dot{\mathrm{V}}_{\mathrm{E}} \max$ or $\dot{\mathrm{V}}_{\mathrm{O}_{2}} \mathrm{max}$, but there were highly significant differences $(p<0.01)$ between ID, BR and the different degrees of complaint of dyspnea in either workers or patients. Regression analysis showed that the degree of breathlessness is related to ID and BR ( $\mathrm{P}<0.01)$. We used ID $>70 \%$ or BR $<25 \mathrm{l} / \mathrm{min}$ as abnormal criteria ${ }^{3)}$ and determined the frequency of dyspnea veri- 
Table 4. Relationship between ID, BR and breathlessness.

\begin{tabular}{llrcr}
\hline & & \multicolumn{3}{c}{ Breathlessness Grade } \\
\cline { 3 - 5 } & & 0 & 1 & 2 \\
\hline \multirow{2}{*}{ No. } & $\mathrm{W}$ & 76 & 71 & 6 \\
& $\mathrm{P}$ & 9 & 38 & 15 \\
Age & $\mathrm{W}$ & 41.8 & 43.5 & 45.2 \\
& $\mathrm{P}$ & 51.2 & 52.6 & 56.4 \\
$\mathrm{ID}(\%)$ & $\mathrm{W}^{*}$ & 52.5 & 60.5 & 75.5 \\
& $\mathrm{P}^{*}$ & 62.1 & 69.3 & 81.7 \\
BR (1/min) & $\mathrm{W}^{*}$ & 52.9 & 36.7 & 20.9 \\
& $\mathrm{P}^{*}$ & 35.2 & 29.3 & 19.3 \\
\hline
\end{tabular}

$\mathrm{W}$ : workers, P: patients

$* \mathrm{P}<0.05$ comparing breathlessness grades.

Table 5. Frequencies of dyspnea obtained by the questionnaire and exercise testing.

\begin{tabular}{|c|c|c|c|c|}
\hline & \multicolumn{2}{|c|}{ Workers } & \multicolumn{2}{|c|}{ Patients } \\
\hline & Dyspnea + & - & Dyspnea + & - \\
\hline Normal ID and BR & 31 & 70 & 18 & 7 \\
\hline Abnormal ID or BR & 46 & 6 & 35 & 2 \\
\hline$x^{2}$-test & \multicolumn{2}{|c|}{$\mathrm{p}<0.05$} & \multicolumn{2}{|c|}{$\mathrm{p}<0.05$} \\
\hline
\end{tabular}

fied by exercise testing in our subjects (Table 5). Of 77 workers and 53 patients with complaints of dyspnea, only 46 workers and 35 patients were verified to have ventilatory limitation during exercise. Other 31 workers and 18 patients did not have exercising ventilatory limitation although they complained dyspnea. Of those without complaints of dyspnea, 6 workers and 2 patients had ventilatory limitation during exercise. According to the results, 30\% workers and 56\% patients should be slight or moderate breathlessness verified by ID and BR, which were $20 \%$ and $29 \%$ each less than those derived from the questionnaire on dyspnea. The different proportions between subjective complaint objective physiological measurements were statistically significant for both workers and patients.

\section{Discussion}

Since the most common symptom in those claiming respiratory disability is shortness of breath, it should be taken into account when we assess functional impairment and disability induced by silica exposure. Questions on breathlessness have 
been used in epidemiological surveys for decades. The most immediate reason for this is probably that they are both cheap and little time-consuming. Although fairly reproducible in an individual, dyspnea on exertion is a subjective sensation and varies widely among subjects ${ }^{6}$. Therefore, it is important to find objective measurement to evaluate and quantify the dyspnea in the workers exposed to silica who are seeking compensation and work rearrangement. The relationships between complaints of dyspnea and resting pulmonary function testing in workers exposed to silica have been reported by some authors ${ }^{4,7,8)}$. However, since abnormalities responsible for exertional dyspnea may not be apparent on tests at rest, the abnormalities may be expressed genuinely by means of exercise testing which are objective and are not influenced by the behavior of the subject. Exercise test had been used to assess cardiopulmonary function and identify the cause of dyspnea in clinical medicine for a long time but it was only in recent decade to be introduced into occupational medicine. So far, there has not been any paper which reported evaluating dyspnea in silica-exposed workers by means of exercise testing. In this study, we used exercise testing in the subjects without dyspnea and with slight or moderate dyspnea by questionnaire. We would like to understand the relationship between exercise testing and complaint of dyspnea and to reveal its role in evaluating dyspnea in silica-exposed workers.

In spite of the fact that exercise testing had generally been done in laboratories with blood gas analyzers and other instruments, we performed the noninvasive exercise testing in the workplace in this study. We selected a progressive incremental test on bicycle ergometer and worked out the exercising scheme used in the workplace according to the available condition. Because a sub-maximal testing may lead to a better level of cooperation, and there is probably less risk ${ }^{9}$, we selected it in our subjects. That our findings were similar to some other authors' ${ }^{10,11)}$ indicated that the exercise scheme in this study was comparable and practical. The patients with silicosis had obviously lower exercise tolerance and poorer exercising pulmonary function than did the workers without silicosis. Because the mean age of the patients was 10 years older than that of the workers, the observed differences between the two groups might be the results of confounding by age and we could not further discuss about the difference. However, the emphasis of this study was the relationship of exercise testing as an objective physiological measurement with subjective dyspnea in the workers exposed to silica, rather than the comparison of the workers with the patients.

Other authors has indicated that exercise testing might be helpful in assessing the physiological basis for the subjective complaint of exertional dyspnea in clinical patients ${ }^{12)}$. Because the complaints of dyspnea are often occurring during exercise, it is likely that a diagnostic test performed during exercise rather than at rest would have an advantage. Some studies ${ }^{13-15)}$ have shown that pulmonary func- 
tion test at rest alone do not necessarily reflect the severity of respiratory impairment, quantitatively. The ventilation measured during exercise would improve accuracy of impairment evaluation. In subjects with respiratory disease, ventilatory and gas exchange disturbances predominate and may contribute to the sensation of exertional dyspnea by increased ventilatory demand. In our study, the consistent association of ID, BR with complaint of dyspnea was clearly indicated. With the increasing degree of dyspnea for either workers or patients, ID increased significantly and BR decreased. Nonetheless, the proportion of dyspnea from questions was much higher than that verified by ID and BR. It confirmed that obvious difference existed between subjective complaint and objective physiological testing. Some authors reported that subject's motivation might influence the complaints of symptoms. Should the subjects be claiming compensation, then he tends to exaggerate his symptoms ${ }^{16)}$. This was first quantified by Cotes ${ }^{17)}$ when he related the degree of breathlessness in two groups of subjects, one was claiming compensation while the other had consulted the physician for respiratory symptoms. For the same level of subjective complaint of dyspnea, those claiming compensation had appreciably better mean forced expiratory volume in one second $\left(\mathrm{FEV}_{1}\right)$ than those who consulted the physician for other reasons. Although our subjects were not claiming compensation at the time of examination, they had knowledge about the harmful nature of silica. Therefore, we could not exclude the possibility that some of them exaggerated their complaints.

ID and BR as comparison of ventilatory capacity during exercise testing ( $\left.\dot{\mathrm{V}}_{\mathrm{E}} \mathrm{max}\right)$ to theoretical maximum (MVV) may have particular value in evaluating exertional dyspnea in workers exposed to silica. There was trend towards use of a higher proportion of potential maximal ventilatory capacity (MVV) at the end of exercise in those with dyspnea in our study. ID and BR mainly express an insufficient ventilatory capacity for the increase of ventilatory demand in dyspneic patients during exercise ${ }^{18)}$. The increase in ventilatory demand was presumably due to an increase in dead space ventilation secondary to ventilation-perfusion mismatching, and decreasing oxygen in blood stimulates the peripheral respiratory receptors to impel breath to speed up. Exercise testing probably is unnecessary for the workers either with severe subjective dyspnea that can be easily observed or without dyspnea. However, in the range of mild to moderate subjective dyspnea, exercise testing may provide objective information to help evaluate dyspnea in workers exposed to silica. According to our previous study ${ }^{5)}$ and other studies ${ }^{19}, 20$, we proposed that the degree of dyspnea could be classified into: slight dyspnea: ID $70-80 \%$, or BR 15-25 1/min; moderate dyspnea or above: ID > 80\% or $\mathrm{BR}<15 \mathrm{l} / \mathrm{min}$.

This is the first study to show the relationship between dyspnea and exercise testing in silica-exposed workers. We found a consistent association of exercising ventilatory limitation with complaint of dyspnea, but the proportion of sub- 
jective dyspnea was significantly higher than that determined by exercise testing. It suggests that objective physiological measures like exercise testing may be of value in evaluating dyspnea in silica-exposed workers.

\section{REFERENCES}

1) Murphy RL, Gaensler EA, Ferris BG. Diagnosis of asbestosis. Observations from a longitudinal survey of shipyard pipe coverers. Am J Med 1978; 65: 488-92.

2) Mahler DA, Harver A. Clinical measurement of dyspnea. In: DA Mahler, editor, Dyspnea. Mt, Kisco, NY: Futura Publishing 1990, 75-126.

3) Koskinen H. Symptoms and clinical findings in patients with silicosis. Scand J Work Environ Health 1985; 11: 101-6.

4) Musk AW, Rouse IL, Rivera B, Klerk NHde, McNulty JC. Respiratory disease in non-smoking western Australian goldminers. Br J Ind Med 1992; 49: 750-4.

5) Wang XR, Wang MZ, Wang ZM. Evaluation of dyspnea in pneumoconiosis patients. Chinese J Ind Hyg Occup Dis 1991; 17: 160-2.

6) Adams L, Chronos N, Lane R, Guz A. The measurement of breathlessness induced in normal subjects: validity of two scaling techniques. Clin Sci 1985; 69: 7-16.

7) Soutar C, Campbell S, Gurr D, Lloyd M, et al. Important deficits of lung function in three modern colliery populations. Relations with dust exposure. Am Rev Respir Dis 1993; 147: 797-803.

8) Lemle A, de Araujo AJ, Lapa e silva JR, et al. Respiratory symptoms and spirometric tests of quarry workers in Rio de Janeiro. Rev Assoc Med Bras 1994; 40: 23-35.

9) Wiedeman HP, Gee JBL, Balmes JR, Loke J. Exercise testing in occupational lung disease. Clin Chest Med 1984; 5: 157-71.

10) Hansen JE, Sue DY, Karlman W. Predicted values for clinical exercise testing. Am Rev Resir Dis 1984; 129: (Suppl.) S49-S55.

11) John H, Zeb M, Brown HV. Role of exercise testing in assessing functional respiratory impairment due to asbestos exposure. J Occup Med 1982; 24: 685-9.

12) Wassermank, Whipp BJ. State of the art: Exercise physiology in health and disease. Am Rev Respir Dis 1975; 112: 29.

13) Oren A, Sue DY, Hansen JE, Torrance DJ, Wasserman K. The role of exercise testing in impairment evaluation. Am Rev Respir Dis 1987; 135: 230-5.

14) Dillard TA. Ventilatory limitation of exercise. Prediction in COPD. Chest 1987; 92: 195-6.

15) Cotes JE, Zejda J, King B. Lung function impairment as a guide to exercise limitation in workrelated lung disorders. Am Rev Respir Dis 1988; 137: 1089-93.

16) Londgren I, Mueller B, Gaensler EA. Pulmonary impairment and disability claims. JAMA 1965; 194: 210-7.

17) Cotes JE: Assessment of disablement due to impaired respiratory function. Bull Physiopathol Respir 1975; 11: 210-7.

18) Sue DY, Wasserman K. Impact of integrative cardiopulmonary exercise testing on clinical decision making. Chest 1991; 99: 981-92.

19) Cotes JE. Lung function: assessment and application in medicine. 4th ed, Oxford; Blackwell Scientific $1979 ; 1-570$.

20) Blackie SP, Faribarn MS, McElvaney NG, et al. Normal values and ranges for ventilation and breathing pattern at maximal exercise. Chest 1991; 100: 136-42. 